\title{
Trends in corrosion protection of materials
}

\author{
K BALAKRISHNAN \\ Central Electrochemical Research Institute, Karaikudi 623006, India
}

\begin{abstract}
The rapid advances in technologies in various fields have also recorded significant progresses in the field of newer materials as the reliability and effective performance of industrial equipment as well as the associated components mostly depend upon their integrity over specified period.

Though the basic methods of protection of materials like use of corrosion-resistant alloys, application of surface coatings, modification of the environment and application of cathodic protection have largely remained the same, the approaches and techniques adopted in each of these fields have been so advanced that one could today advocate appropriate protection systems with high reliability and performance.

The author presents some of his contributions along with his colleagues in the fields of cathodic protection of vital structures, development of newer coatings for specific applications and new approaches to corrosion monitoring techniques, besides highlighting the corrosion behaviour of some of the heat-treated alloys which are specifically used in such strategic areas as space and defence.

The presentation would also cover briefly some of the techniques that have been employed by the author for better understanding of corrosion and passivation of metals and alloys.
\end{abstract}

Keywords. Corrosion protection; materials.

\section{Corrosion audit and corrosion control}

Corrosion audit and corrosion control have become the watchwords of the major industrial sectors in view of their major impact on the performance and capacity of industrial plants. It is being increasingly realized that application of the existing knowledge on corrosion control alone can bring about substantial savings in the cost of maintenance and repair, besides ensuring quality products with minimum financial inputs.

Corrosion of metals and alloys is still controlled by conventional methods like application of surface coatings, use of inhibitors, application of electrochemical protection methods, besides the use of more corrosion-resistant materials for specific applications. However, better understanding of corrosion processes and also the techniques involved in control of the same have led to the use of more efficient methods at less cost. The current presentation will highlight some of the achievements of the author in collaboration with colleagues in various aspects of the development of anti-corrosion technologies as well as the understanding of the mechanism of corrosion and passivation.

\section{Electrochemical protection}

Cathodic protection and anodic protection are being increasingly employed in industries for control of corrosion of highly corrodable steel in typical environments at low costs. These methods obviously avoid the use of other, costlier methods like 
surface coatings and inhibitors, though a combination of these techniques would be more economical and beneficial in many cases. Of the two methods, cathodic protection is more widely employed, as this is based on bringing about immunity to corrosion through understanding the thermodynamics of corrosion processes. Moreover, this method is practicable under almost all conditions where cathodic polarization can be achieved at optimum current densities.

Anodic protection, on the other hand, is based on the ability of the metal or alloy to get passivated in the given medium, when polarized over a fairly wide range of anode potential. This would immediately suggest that this method can be employed only in cases where anodic passivation is economically feasible. This type of protection is, however, employed in chemical and engineering industries for the protection of steel and stainless steel in acids and a few other processing chemicals. CECRI has designed an anodic protection system ${ }^{1}$ with the automatic control of potential for sulphuric acid heat-exchangers made of either steel or stainless steel. Extensive studies were carried out to evaluate the design parameters like critical current, passivation current and the potential range of the passivation under different conditions of concentration of acids, temperature and velocity, and these were the main inputs for the above design.

\section{Cathodic protection}

Cathodic protection is the only foolproof method of protection of inaccessible structures like underground pipelines and marine structures like offshore platforms and rebars in concrete, apart from industrial equipment like heat-exchangers in chemical industries. Though cathodic protection can be achieved either by sacrificial anode or impressed current system, the choice is obviously based on economics as well as practical considerations.

CECRI has, over the years, developed the total technology for cathodic protection contributing to the development of galvanic anodes, impressed current anodes, and automatic control and monitoring system, besides providing technical assistance to various industrial sectors on the design of cathodic protection for industrial structures.

\subsection{Galvanic anodes}

The three major types of galvanic anodes based on aluminium, magnesium and zinc have been extensively studied, leading to the development of the above anodes which are already in commercial production in the country. These anodes have shown better performance in terms of improved anode efficiency and more uniform self-corrosion.

\subsection{Impressed current anodes}

Though various types of impressed current anodes are in vogue, CECRI has, for the first time, employed the TSIA, developed at CECRI for the chlor-alkali industry for use in cathodic protection of marine structures, replacing the conventional leadantimony-silver alloy anodes. The TSIA have performed extremely well during the past five years since their installation and are still performing well. It is hoped 


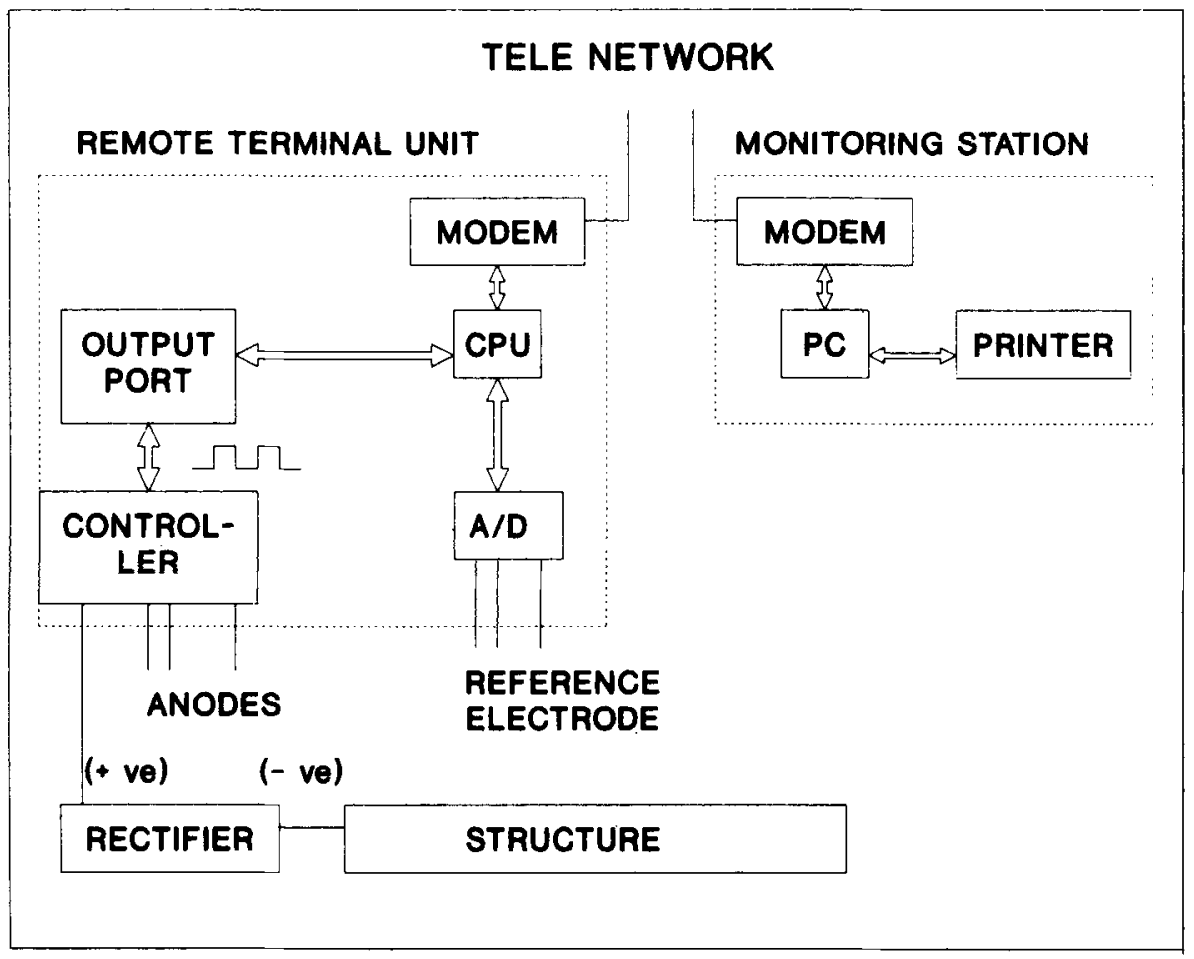

Figure 1. Block diagram of automatic control system for cathodic protection.

that these types of anodes, costing and weighing less than conventional anodes, would be more widely employed for the protection of both underground and marine structures. As an experimental measure, CECRI has made use of the same anode for the protection of agricultural tubewells in Tamil Nadu. The other development of CECRI in anodes for chlorate industries, viz. the lead dioxide coated graphite electrode, was also tested successfully for use in cathodic protection of underground structures.

CECRI has evolved, through the years, different types of automatic control systems for cathodic protection starting from the use of SCR to the use of SCADA, the most recent development. The supervisory control and data acquisition (SCADA) system helps in the remote monitoring and control of cathodic protection system, either through telephone networks or through satellite communication (figure 1). The system has its own software package for control, monitoring, diagnosis of faults and also acquisition of data with facilities to monitor 16 points (reference electrodes) at the same time. The above SCADA has already been tested in the field for the protection of jetties at Madras Port Trust and was also demonstrated to officials of the Oil and Natural Gas Commission (ONGC) by connecting it to satellite communication. The main advantage of this system is that it uses a pulsed current as a result of which the potentials could be measured and controlled during off-stage, eliminating the IR drop, which usually causes error in measurement in conventional methods. It is hoped that this system would be widely used in the near future in the country for the protection of long oil pipelines as well as strategic marine structures. 


\section{Development of coatings}

Surface coatings have been occupying a key position as a major method of corrosion control in the industrial world. It is estimated that $40 \%$ of the cost of corrosion control is accounted for by this method. The three components that are involved in the realization of the best performance for any coating system include a clean and good surface, use of the most appropriate painting system, and the proper method of application, including the period of application. CECRI has done considerable work in all these fields and has developed a few anti-corrosive primers ${ }^{6.7}$, rust converters $^{8}$ and rust converting primers ${ }^{9,10}$ and coatings for specific applications like high-temperature resistance ${ }^{11}$, radiation resistance ${ }^{12}$, chemical resistance, etc.

\subsection{Conversion coatings}

Conversion coatings have played a major role in surface preparation as well as in providing temporary protection. Chromic acid has been the cheapest and the most efficient chemical used in the passivation of non-ferrous metals like aluminium, zinc and cadmium. However, environmental regulations have put a stop to the use of these toxic chemicals in all their applications including inhibitors and primers. CECRI has been able to develop a non-chromate formulation for passivating zinc and aluminium ${ }^{13}$, making them suitable for subsequent painting or making them appear better temporarily for consumer applications. This method is based on the use of other oxidation agents like permanganate, molybdate, etc. in combination with other activating agents.

\section{Water-treatment chemicals}

Water is used in many industries for various applications such as steam generation, cooling, secondary recovery of oils and pressure testing of equipments. Water used for these purposes has to be properly treated for keeping the extent of corrosion to acceptable levels, besides eliminating the possibility of scale formation. Formulations avoiding chromate and toxic biocides have been developed by CECRI as a total package for various industrial uses.

In this context, it should be mentioned that control of fouling and biocorrosion plays a major role in the performance of heat exchangers. Systematic investigations have been carried out for identifying the effective biocide and also for monitoring the same in industrial conditions ${ }^{14}$.

\section{Corrosion behaviour of some heat-treatable alloys}

The corrosion resistance of heat-treatable alloys depends upon the heat treatment condition. Corrosion resistance is maximum when the material is in solution heat treated condition. Aging (heat treatment) decreases corrosion resistance. This is due to the formation of precipitates during aging which makes the material heterogeneous. The corrosion behaviour of the material is dependent upon the aging condition-whether the material is underaged, peakaged or overaged. The results of the investigations 
Table 1. Effect of heat treatment on corrosion behaviour.

\begin{tabular}{lccc}
\hline $\begin{array}{l}\text { Type of heat } \\
\text { treatment }\end{array}$ & $\begin{array}{c}\text { Heat treatment } \\
\text { condition }\end{array}$ & $\begin{array}{c}\text { Corrosion current } \\
\text { by polarization } \\
\text { technique }\left(\mu \mathrm{A} / \mathrm{cm}^{2}\right)\end{array}$ & $\begin{array}{c}R_{c t}\left(\mathrm{~K} . \text { ohm.cm }^{2}\right) \\
\text { by impedance } \\
\text { technique }\end{array}$ \\
\hline $\begin{array}{l}\text { Solution } \\
\text { annealed }\end{array}$ & - & $0 \cdot 15$ & $>30$ \\
$\begin{array}{l}\text { Underaged } \\
\text { Peakaged }\end{array}$ & $450^{\circ} \mathrm{C}, 4 \mathrm{~h}$ & 3 & $3 \cdot 1$ \\
Overaged & $450^{\circ} \mathrm{C}, 5 \mathrm{~h}$ & $3 \cdot 3$ & $2 \cdot 2$ \\
\hline
\end{tabular}

Table 2. Effect of electropolishing on corrosion behaviour.

\begin{tabular}{lccc}
\hline $\begin{array}{l}\text { Type of heat } \\
\text { treatment }\end{array}$ & $\begin{array}{c}\text { Heat treatment } \\
\text { condition }\end{array}$ & $\begin{array}{c}\text { Corrosion current } \\
\text { by polarization } \\
\text { technique }\left(\mu \mathrm{A} / \mathrm{cm}^{2}\right)^{*}\end{array}$ & $\begin{array}{c}R_{\mathrm{ct}}(\mathbf{K} . \text { ohm.cm } \\
\text { by impedance } \\
\text { technique }\end{array}$ \\
\hline Underaged & $450^{\circ} \mathrm{C}, 4 \mathrm{~h}$ & $0 \cdot 18(3)$ & $36(3 \cdot 1)$ \\
Peakaged & $450^{\circ} \mathrm{C}, 5 \mathrm{~h}$ & $0 \cdot 18(3 \cdot 3)$ & $32(2 \cdot 2)$ \\
Overaged & $450^{\circ} \mathrm{C}, 7 \mathrm{~h}$ & $0 \cdot 13(2)$ & $80(4 \cdot 3)$ \\
\hline
\end{tabular}

*Values in parentheses correspond to those in table 3.

Table 3. Pitting corrosion behaviour of stainless maraging steel.

\begin{tabular}{lccc}
\hline $\begin{array}{l}\text { Type of heat } \\
\text { treatment }\end{array}$ & $\begin{array}{c}\text { Heat treatment } \\
\text { condition }\end{array}$ & $\begin{array}{c}\text { Pitting potential } \\
(\mathrm{mV}) \text { vs SCE }\end{array}$ & $\begin{array}{c}\text { Protection } \\
\text { potential } \\
(\mathrm{mV}) \text { vs SCE }\end{array}$ \\
\hline $\begin{array}{l}\text { Underaged } \\
\text { Peakaged }\end{array}$ & $\begin{array}{l}450^{\circ} \mathrm{C}, 4 \mathrm{~h} \\
450^{\circ} \mathrm{C}, 5 \mathrm{~h}\end{array}$ & +50 & -75 \\
$\begin{array}{l}\text { Overaged } \\
\text { Effect of electropolishing }\end{array}$ & $450^{\circ} \mathrm{C}, 7 \mathrm{~h}$ & +250 & 0 \\
$\begin{array}{l}\text { Underaged } \\
\text { Peakaged }\end{array}$ & $450^{\circ} \mathrm{C}, 4 \mathrm{~h}$ & +650 & +650 \\
Overaged & $450^{\circ} \mathrm{C}, 5 \mathrm{~h}$ & +660 & +660 \\
& $450^{\circ} \mathrm{C}, 7 \mathrm{~h}$ & +750 & +750 \\
\hline
\end{tabular}

Table 4. Constant load SCC test data.

\begin{tabular}{lc}
\hline Aging & Time to failure (h) \\
\hline Underaged $\left(450^{\circ} \mathrm{C} / 4 \mathrm{~h}\right)$ & $10-13$ \\
Overaged $\left(450^{\circ} \mathrm{C} / 7 \mathrm{~h}\right)$ & 324 \\
\hline
\end{tabular}

Stress : $80 \%$ of proof stress

Medium : $\quad 5 \% \mathrm{NaCl}$ solution 
carried out on some heat-treatable alloys-stainless maraging steel in chloride environments ${ }^{15}, 7020$ aluminium alloy in $\mathrm{N}_{2} \mathrm{O}_{4}$ environment and $\mathrm{AA} 6061$ aluminium alloy $^{16}$ in humid environment - are presented in this paper.

\subsection{Corrosion behaviour of stainless maraging steel}

The effect of heat treatment on the corrosion behaviour of stainless maraging steel and also the effect of electropolishing on the corrosion behaviour are given in tables 1 and 2 . It may be seen that overaging for $7 \mathrm{~h}$ which produces the same hardness as underaging in $4 \mathrm{~h}$ gives rise to lower corrosion, higher pitting potential and better resistance to stress corrosion cracking (tables 1-4).

\subsection{Corrosion behaviour of 7020 Al alloys for $\mathrm{N}_{2} \mathrm{O}_{4}$}

The studies carried out at CECRI have indicated that the general as well as stress corrosion behaviour of this alloy can be reasonably monitored by choosing the appropriate weld metals, as shown in table 5 .

Table 5. Corrosion rates of the 7020 parent metal and welds after 30 days of immersion in liquid $\mathrm{N}_{2} \mathrm{O}_{4}$.

\begin{tabular}{ll}
\hline $\begin{array}{l}\text { Parent metal/weld with } \\
\text { filler metal }\end{array}$ & Rate (mmpy) \\
\hline Parent metal & 0.004 \\
AG 4.5 Mn & 0.006 \\
AG 4Z2 & 0.004 \\
AG 5 & 0.040 \\
\hline
\end{tabular}

Table 6. Cleaning efficiency of various baths.

\begin{tabular}{|c|c|c|c|c|}
\hline $\begin{array}{l}\text { Composition of } \\
\text { cleaning } \\
\text { solution }\end{array}$ & $\begin{array}{c}\text { Temperature } \\
\left({ }^{\circ} \mathrm{C}\right)\end{array}$ & $\begin{array}{l}\text { Duration } \\
\text { (min) }\end{array}$ & $\begin{array}{l}\text { Rate of } \\
\text { attack } \\
(\mu \mathrm{m})\end{array}$ & Remarks \\
\hline $4 \% \mathrm{NaOH}$ & 30 & 2 & $1 \cdot 13$ & $\begin{array}{l}\text { Black stains } \\
\text { remain }\end{array}$ \\
\hline $10 \% \mathrm{H}_{3} \mathrm{PO}_{4}$ & 30 & 15 & 1.03 & Clean \\
\hline $\begin{array}{l}\text { Sodium hydroxide }(4 \%) \\
+ \text { sodium metasilicate } \\
(1.45 \%)\end{array}$ & 30 & 15 & $0 \cdot 85$ & Partly cleaned \\
\hline $3 \% \mathrm{CrO}_{3}+10 \% \mathrm{H}_{2} \mathrm{SO}_{4}$ & 85 & 2 & $2 \cdot 14$ & Clean surface \\
\hline $50 \% \mathrm{HNO}_{3}(1: 1)$ & 30 & 15 & $0 \cdot 2$ & $\begin{array}{l}\text { Stains not } \\
\text { removed } \\
\text { completely }\end{array}$ \\
\hline $50 \% \mathrm{HNO}_{3}(1: 1)$ & 30 & 60 & 1.02 & $\begin{array}{l}\text { Stains } \\
\text { completely } \\
\text { removed }\end{array}$ \\
\hline
\end{tabular}


Table 7. Performance of coated 6061 aluminium alloy in accelerated condensation test $\left(\mathrm{RH} 100 \%\right.$ at $\left.50^{\circ} \mathrm{C}\right)$.

\begin{tabular}{|c|c|c|}
\hline Type of treatment & Time to stain & $\begin{array}{l}\text { Surface appearance } \\
\text { after } 30 \text { days }\end{array}$ \\
\hline Without treatment & $30 \mathrm{~min}$ & Severely stained \\
\hline Permanganate & $\begin{array}{l}\text { Pits initiated } \\
\text { in } 5 \text { days }\end{array}$ & Severely pitted \\
\hline Molybdate & 5 days & Severely stained \\
\hline Chromate & 30 days & Not affected \\
\hline $\begin{array}{l}\text { Passivation treatment } \\
\text { by } \mathrm{HNO}_{3}\left(50 \% \mathrm{HNO}_{3}\right. \\
\text { for } 1 \mathrm{~h})\end{array}$ & 2 days & Staining initiated \\
\hline
\end{tabular}

The stress corrosion test carried out by 4-point loading over 100 days as well as the constant load test for $6 \mathrm{~h}$ have indicated that AG4Z2 weld metal had higher resistance than the other weld materials.

\subsection{Staining of 6061 alloy in humid environments}

The causes for the staining of these alloys which are used as fuel containers were examined and methods of removal of such stains as well as control of formation of such stains through the formation of various types of conversion coatings were demonstrated (table 7).

\section{Corrosion control in concrete structures}

Concrete structures were expected to last for a minimum of 100 years as either deterioration of concrete or corrosion of rebars in an alkaline environment was not anticipated. However, failures of major concrete structures in such short spans of time as five years have been reported from all over the world.

CECRI has been giving a lot of attention to the causes and the mechanism of corrosion of concrete structures since the 1960 s and these studies have led to the development of a number of anti-corrosion technologies and techniques for monitoring corrosion. The former includes the development of protective coatings for rebars based on cement slurry and inhibitors ${ }^{17}$ which have been made mandatory for all major bridges and other constructions in the country by the Ministry of Surface Transport (MOST). This technology which has been released to more than 10 industries has now been superseded by the development of a cement-polymer composite coating ${ }^{18}$. This has specific advantages over other coatings. This coating can be applied also on rusty steel. It can be applied in the shop and is suitable for use in prestressing steel wires also.

The causes and extent of deterioration of concrete as well as the corrosion of rebars in different environments have been extensively studied. These studies have led to the development of appropriate technologies for rehabilitation of the distressed structures. Another major contribution of CECRI in this field has been the develop- 
ment and use of techniques for monitoring corrosion of rebars and prestressing steel wires. Resistivity measurement for characterizing the quality of concrete and also for evaluating the condition of prestressing steel wire, development of corrosion monitoring probes with appropriate data acquisition systems, and development of linear polarization technique for corrosion rate measurement are worth mentioning as they are already being installed for continuous monitoring of the corrosion behaviour of major bridges in the country ${ }^{19}$.

\section{Mechanistic aspects of corrosion}

It is said that understanding the cause of the problem provides more than $50 \%$ of the answer to any corrosion problem. A number of electrochemical and physicochemical techniques have been employed for understanding the mechanism of corrosion of metals and alloys in different environments. However, specific mention might be made of the use of rotating ring disk electrode for understanding the mechanism of selective dissolution of alloys ${ }^{20}$, spectroelectrochemical investigations for characterizing the passive film, especially in terms of its composition and electronic behaviour ${ }^{21}$, and use of such techniques as noise analysis ${ }^{22}$ and impedance measurement 23,24 for rapid evaluation of corrosion behaviour of metals and alloys.

\section{References}

1. Design and anodic protection system for stainless steel heat exchangers in sulphuric acid industry B Sathianandham, K R Ramakrishnan, Y Mahadeva lyer and K Balakrishnan-Proc. of 10th International Congress on Metallic Corrosion, Madras, vol. 3 (1987) p. 2617

2. Improvements in or relating to a process for the preparation of a new $\mathbf{A l}-\mathrm{Zn}$-In ternary alloy galvanic anode for the cathodic protection of structures submerged in sea water and in sea-mud - V Kapali, K N Srinivasan, B Venkataraman, K Balakrishnan and K I Vasu

This anode is used in places where use of mercury is prohibited. The anode with this composition can be employed though with a lower anode efficiency than that of $\mathrm{Al}-\mathrm{Zn}-\mathrm{Hg}$ anode

3. An alloy of magnesium containing misch metal for use as galvanic anode- $N$ Subramanyan, K Balakrishnan, S Venkatakrishna Iyer and M Krishnan

Process for preparation of improved alloy of magnesium for use as galvanic anode - Indian Patent No. 146925 dated 7.9 .1977

N Subramanyan, K Balakrishnan, S Venkatakrishna Iyer and M Krishnan - This patent deals with the use of rare-earth metals in the production of magnesium alloy anodes which gives an anode efficiency of $65 \%$

4. Improvements in or relating to a process for the preparation of a new $\mathrm{Al}-\mathrm{Zn}$-In ternary alloy galvanic anode for the cathodic protection of structures submerged in sea water and in sea-mud - V Kapali, K N Srinivasan, B Venkataraman, K Balakrishnan and K I Vasu

This anode is used in places where use of mercury is prohibited. The anode with this composition can be employed though with a lower anode efficiency than that of $\mathrm{Al}-\mathrm{Zn}-\mathrm{Hg}$ anode

5. Improvements in or relating to on-line control of cathodic protection - S Vincent, S P Manoharan and $\mathrm{K}$ Balakrishnan

Improvements in or relating to supervisory control and data acquisition cathodic protection S P Manoharan, S Vincent and $\mathbf{K}$ Balakrishnan

6. Indian patent No. $348 / \mathrm{Del} / 79$

7. Proc. of the 12th seminar on Electrochemistry - K S Rajagopalan et al (March 1972, Karaikudi) pp. 214-255

8. Indian patent No. IP 142923

9. Improvements in or relating to the preparation of rust-converting primer (Indian patent No. 258/Dec/87) 
10. Improvements in or relating to the preparation of rust-converting primer (Patent No. 258/Dec/87)

11. L Mathivanan, M Selvaraj, S Syed Azi and K Balakrishnan, Bull. Electrochem. 1993949

12. Radiation and corrosion resistant coatings for nuclear power stations invention intelligence April, 1989 , pp. $180-182$

13. C Marikkannu, Ph. D., thesis (1994)

14. Development of improved economical water treating chemicals, Report submitted to IOGPT, ONGC, Bombay

15. C Marikkannu and $\mathrm{K}$ Balakrishnan, 12th International Corrosion Congress, vol. III A, (Houston: National Association of Corrosion Engineers, 1992), p. 1124

16. "Corrosion behaviour of ANFOR 7020 aluminium alloys in $\mathrm{N}_{2} \mathrm{O}_{4}$ ", CECRI Project Report 1987; "Suggestion of suitable chemical treatment for removal and prevention of black stains of AA 6061 aluminium alloy propulsion tanks", CECRI Project Report, July 1993

17. (a) Inhibited and sealed cement slurry coating of steel rebar - a state of art report

N S Rengaswamy, S Srinivasan and T M Balasubramanian, Transaction of the SAEST, Vol. 23, No. 2-3, April-Sept. 1988, pp 163-173

(b) Indian patent No. $465 / \mathrm{Cal} / 75$

(c) Indian patent No. 109897

(d) Indian patent No. 109784

(e) Indian patent No. 112440

18. (a) Corrosion protection of prestressing steel in bridges and structures: Technologies developed at CECRI, Karaikudi - N S Rengaswamy, K Kumar, S Ramu, S Pitchumani, R Vedalakshmi and K Balakrishnan, ICI Bulletin, No. 45, December 1993

(b) Indian patent No. 481/Del/93

(c) Indian patent No. 259/Del/93

19. Newer approaches to corrosion control in concrete structures - K Balakrishnan and N S Rengaswamy 11th International Corrosion Congress, 2-6 April 1990, Florence, Italy

20. Anodic behaviour of copper - K Balakrishnan and V K Venkatesan, 1977 Trans. SAEST, 12, 4, 221 Anodic behaviour of brass - A ring-disc study $K$ Balakrishnan and V K Venkatesan - Werk und Korrosion (W.G.) Vol. 29, p. 113 (1978)

Cathodic reduction of oxygen on copper and brass $\mathrm{K}$ Balakrishnan and V K Venkatesan Electrochemica Acta 197924131

21. S Sathiyanarayanan, S P Manoharan, G Rajagopal and K Balakrishnan, 1992 Br. Corros. J. 27172

22. Studies on pitting corrosion by noise measurements $\mathbf{S}$ Muralidharan, S P Manoharan, G Venkatachari and K Balakrishnan Bull. Electrochem. 199064

23. Impedance behaviour of some copper alloys and monel in synthetic seawater-M Natesan, G Venkatachari, T M Balasubramanian and K Balakrishnan-Bull. Electrochem. 19884221

24. Optimization of cathodic protection potential of steel welds by electrochemical impedance technique G Sozhan, S Ramu, K N Krishnan and K Balakrishnan 10th European Corrosion Congress, Spain, March 1993 